\title{
Our percutaneous nephrolitotomy experience in patients with horseshoe kidney
}

\author{
Tufan Suelozgen, Cemal Selcuk Isoglu, Hakan Turk, Mehmet Yoldas, Ozlem Yusuf Ilbey, Ferruh Zorlu \\ Tepecik Training and Research Hospital, Urology Clinic, Izmir, Turkey.
}

\begin{abstract}
Summary Objectives: Horseshoe kidney is the most common renal congenital fusion anomaly. Kidney stone formation is more common in horseshoe kidneys and some of them requires surgical procedure. So we want to evaluate the results of PNL in patients with horseshoe kidney anomaly.

Matherial and method: Between January 2009- January

2014 PNL operation was performed in 6 patients with horseshoe kidney anomaly in our clinic. Success of surgery and postoperative/peroperative complications were evalutaed retrospectively.

Results: No severe complications occured in any patient caused by surgery. Three patients became stonefree. One patient had less than $4 \mathrm{~mm}$. residual stone, two patients had more than $4 \mathrm{~mm}$. residual stone.

Conclusion: PNL is safe surgical method and it can be performed successfully in patients with horseshoe kidney anomaly.
\end{abstract}

KEY WORDS: Horseshoe kidney; Stone formation; Percutaneous nephrolithotomy.

Submitted 2 September 2014; Accepted 3 November 2014

\section{INTRODUCTION}

Horseshoe kidney is the most common renal congenital fusion anomaly with a incidence of $1 / 400$. In $95 \%$ of cases fusion is in the lower pole of kidney. It is 2 times more common in males $(1,2)$. Most of the patients are asymptomatic. Symptoms come out because of kidney stone formation, infection caused by kidney stone and obstruction. Kidney stone formation is more common in horseshoe kidneys and some of them requires surgical procedure (3-5). ESWL treatment can be used in stones up to $2 \mathrm{~cm}$ in horseshoe kidneys. In literature there are studies that shows success rates between 50\%-75\% (5-7). But percutanous nephrolitotomy (PNL) should be the first treatment choise for stones more than $2 \mathrm{~cm}$. In this study, results of PNL in horseshoe kidney patients in our clinic are given.

\section{Matherials AND METHOD}

Between January 2009- January 2014 PNL operation was performed in 6 horseshoe kidney patients. All of the patients had symptoms becasue of stone. Detailed anamnesis was taken and physical diagnosis is performed for each patient. After that biochemical tests including complete blood count, urea, creatinine and urine culture are made. All the patients were evaluated with non-contrast abdomen tomography. Imaging methods requires contrast drugs weren't used. All patients were informed about the operation and informed conset is taken. In opreation morning, second generation cephalosporin antibiotic prophlaxis was performed 1 hour before surgery. Under general anesthesia, 5 Fr. open end uretheral catheter was placed with $22 \mathrm{Fr}$. cystoscope in lithotomy position. And it was fixed to the urinary cathater with silk. Prone position was given to the patient. Contrast material was given from the uretheral catheter and collector system was visualised with fluoroscopy. After planning the access place, biplanar percutanous access was placed with access needle. Tract was dilated with Amplatz dilator over guide wire. $30 \mathrm{Fr}$. Amplatz sheet was placed. Renal collecting system was entered with 22 Fr. rigid nephroscope. Ultrasonic lithotriptor was used to break the stones. Five of 6 patients were have one access. Two access including upper pole intercostal entry and subcostal middle pole entry were performed to one of the patients.

Finally, after evaluation of the fluoroscopic images, $14 \mathrm{Fr}$. mallecot nephrostomy catheter was placed and the operation was terminated.

\section{RESULTS}

All 6 patients were male. Average age was 44,82 (32-63). Four patients (66.6\%) had left, 2 patients (33.3\%) had right kidney stone. Three patients (50\%) had pelvis and lower pole stone, 2 patients (33.3\%) had pelvis stone, 1 patient had pelvis-lower pole and middle pole stone. None of the patients had neither operation nor ESWL history. Average stone size was $1007 \mathrm{~mm}^{2}$ (375-1480), average operation time was $117.1 \mathrm{~min}$. (44-250 min.), average fluoroscopy time was 209 seconds (45-450). Intercostal upper pole access between $11^{\text {th }}$ and $12^{\text {th }}$ ribs was made in 5 patients.

For the patient who had upper middle and lower pole stones; upper pole access was made between 11 and $12^{\text {th }}$ ribs and subcostal access was made to the middle calix under the $12^{\text {th }}$ rib (Table 1). 
Table 1.

Parameters before and after surgery.

\begin{tabular}{|c|c|c|c|c|c|c|}
\hline & Patient 1 & Patient 2 & Patient 3 & Patient 4 & Patient 5 & Patient 6 \\
\hline$\overline{\text { Age }}$ & 32 & 38 & 45 & 47 & 54 & 63 \\
\hline Gender & $\mathrm{M}$ & $\mathrm{M}$ & $\mathrm{M}$ & $M$ & $M$ & $\mathrm{M}$ \\
\hline Stone size $\left(\mathrm{mm}^{2}\right)$ & 975 & 375 & 1115 & 1480 & 900 & 1200 \\
\hline Stone location & $\begin{array}{l}\text { Left kidney pelvis } \\
\text { and lower calyx }\end{array}$ & Left kidney pelvis & $\begin{array}{l}\text { Right kidney pelvis } \\
\text { and lower calyx }\end{array}$ & $\begin{array}{l}\text { Left kidney pelvis, } \\
\text { lower and middle calyx }\end{array}$ & Left kidney pelvis & $\begin{array}{l}\text { Right kidney pelvis } \\
\text { and lower calyx }\end{array}$ \\
\hline Operation time (min.) & 60 & 48 & 90 & 250 & 80 & 175 \\
\hline Fluoroscopy time (sec.) & 50 & 45 & 90 & 450 & 80 & 153 \\
\hline Residual stone size & $<4 \mathrm{~mm}$ & No & No & $6 \mathrm{~mm}$ & No & $7 \mathrm{~mm}$ \\
\hline
\end{tabular}

In 4 patients (66.6\%) there was decrease in hematocrit, Average decrese was 5\% (4-7). But there was no need for blood transfusion. None of the patients had fever and lung complications after surgery. Three patients (50\%) were stonefree in the control non contrast abdominal tomography which performed 1 month after the surgery. One patient had less than $4 \mathrm{~mm}$. (16.6\%) residual stone, 2 patients had averagely $6.5 \mathrm{~mm}$ residual stone (6-7) (Table 1). Becasue of the stones were in the lower pole and didn't casue sypmtoms, additional operation wasn't considered for these 2 patients.

They were being followed-up. Patients were followed with direct X-RAY at intervals of 6 months. Average follow-up time was 25.3 months (6-54). During the follow up period, there was no increase in the stone size of the patients.

\section{Discussion}

Percutanous approach for horseshoe kidney stones was firstly reported by Fletcher et al. in 1973 (8). Yohannes and Smith pointed that ESWL treatment should be chosen for the stones less than $2 \mathrm{~cm}$ in horseshoe kidney, percutanous approach should be chosen when ESWL fails or for bigger stones (9). With the practicing of percutaneous surgery, complications of open surgery is decreased.

The most common complications that can be seen during or after PCNL procedure are fever, bleeding, urine leakage, complications caused by residual stones (10). In our study there was no high fever postoperatively. As is known, because of the vessels of the horseshoe kidney enters the hilum from anteromedial and calyxes rotates to posterior, the vascular injury risk during access is not higher than normal kidney $(11,12)$.

In our patient group decrease of hematocrit was seen in 4 patients (66.6\%) but there was no need for blood transfusion. For the kidneys with normal anatomy upper pole access is generally perfomed from over the $12^{\text {th }}$ rib so intrathoracical complications are more common. Horseshoe kidneys are placed more inferior and far from pleura so access for upper pole becomes more secure. Pneumothorax risk for upper pole access in horseshoe kidneys were found to be $6 \%$ in a study (3). Although all the accesses were made over the $12^{\text {th }}$ rib there was no intrathoracic complication in our study.

In various studies, the success rate after PCNL in horshoe kidneys were reported as $72 \%-85 \%$ and residual stones under $4 \mathrm{~mm}$. were included to the group considered as succesful (13-15). When we consider the residual stones under $4 \mathrm{~mm}$ as successful, our success rate becomes $66,6 \%$ and this result is consistent with the literature.

Before the surgery the stone burden of 2 patients, who had residual stone more than $4 \mathrm{~mm}$, was higher than the others. We think that this situation can be one of the reasons of the significant residual stone.

\section{Conclusion}

PNL is safe surgical method and it can be performed successfully in patients with horseshoe kidney anomaly. Studies with more patients are needed for to make certain conclusions.

\section{REFERENCES}

1. Salas M, Gelet A, Martin X, et al. Horseshoe kidney: the impact of percutaneous surgery. Eur Urol .1992; 21:134-7.

2. Jones DJ, Wickham JE, Kellett MJ. Percutaneous nephrolithotomy for calculi in horseshoe kidneys. J Urol. 1991; 145:481-3.

3. Raj GV, Auge BK, Weizer AZ, et al. Percutaneous management of calculi within horseshoe kidneys. J Urol. 2003; 170:48-51.

4. Evans WP, Resnick MI. Horseshoe kidney and urolithiasis. J Urol. $1981 ; 125: 620-1$.

5. Pitts WR Jr, Muecke EC. Horseshoe kidneys: a 40-year experience. J Urol. 1975; 113:743-6.

6. Clayman RV. Effectiveness of extracorporeal shockwave lithotripsy in the management of stone-bearing horseshoe kidneys. J Urol. 1998; 160:1949.

7. Gallucci M, Vincenzoni A, Schettini M, et al. Extracorporeal shock wave lithotripsy in ureteral and kidney malformations. Urol Int. 2001; 66:61-5. 
8. Fletcher EW, Kettlewell MG. Antegrade pyelography in a horseshoe kidney. Am J Roentgenol Radium Ther Nucl Med. 1973; 119:720-2.

9. Yohannes P, Smith AD. The endourological management of complications associated with horseshoe kidney. J Urol. 2002; 168:5-8.

10.Türk C, Knoll T, Petrik A, et al. Guidelines on Urolithiasis. European Association of Urology, 2013.

11. Segura JW, Patterson DE, LeRoy AJ, et al. Percutaneous removal of kidney stones: review of 1,000 cases. J Urol. 1985; 134:1077-81.
12. Janetschek G, Kunzel KH. Percutaneous nephrolithotomy in horseshoe kidneys. Applied anatomy and clinical experience. $\mathrm{Br} \mathrm{J}$ Urol. 1988; 62:117-22.

13. Lampel A, Hohenfellner M, Schultz-Lampel D, et al. Urolithiasis in horseshoe kidneys: therapeutic management. Urology. 1996; 47:182-6.

14. Al-Otaibi K, Hosking DH. Percutaneous stone removal in horseshoe kidneys. J Urol. 1999; 162:674-7.

15. Lingeman JE, Saw KC: Percutaneous operative procedure in horseshoe kidneys. J Urol. 1999; 161:371.

\section{Correspondence}

Tufan Suelozgen, MD

tsuelozgen@hotmail.com

Cemal Selcuk Isoglu, MD

Hakan Turk, MD

Mehmet Yoldas, MD

Ozlem Yusuf Ilbey, MD

Ferruh Zorlu, MD

Tepecik Training and Research Hospital, Urology Clinic

Izmir, Turkey 